\title{
Determinants of Modern Contraceptive Use and Unmet Need for Family Planning among the Urban Poor
}

\author{
Lavleen Mohan Singh', Shankar Prinja², Pankhuri Rai ${ }^{3}$, Ankita Siddhanta1 ${ }^{*}$, Ajay Kumar Singh1, \\ Atul Sharma ${ }^{2}$, Vineeta Sharma ${ }^{2}$, Saroj Kumar Rana ${ }^{2}$, Kaniz Fatima Muneeza ${ }^{4}$, \\ Akshya Srivastava ${ }^{1}$
}

${ }^{1}$ IPE Global, New Delhi, India

${ }^{2}$ School of Public Health, Post Graduate Institute of Medical Education and Research, Chandigarh, India

${ }^{3}$ Hindustan Latex Family Planning Promotion Trust, Noida, India

${ }^{4}$ Centre for Catalyzing Change (C3 India), New Delhi, India

Email: *ankita.siddhanta@gmail.com

How to cite this paper: Singh, L. M., Prinja, S., Rai, P., Siddhanta, A., Singh, A. K., Sharma, A., Sharma, V., Rana, S. K., Muneeza, K. F., \& Srivastava, A. (2020). Determinants of Modern Contraceptive Use and Unmet Need for Family Planning among the Urban Poor. Open Journal of Social Sciences, 8, 451-473.

https://doi.org/10.4236/jss.2020.85031

Received: March 30, 2020

Accepted: May 26, 2020

Published: May 29, 2020

Copyright $\odot 2020$ by author(s) and Scientific Research Publishing Inc. This work is licensed under the Creative Commons Attribution International License (CC BY 4.0).

http://creativecommons.org/licenses/by/4.0/

(c) (i) Open Access

\begin{abstract}
This study aims to examine modern contraceptive use and unmet need of family planning of urban poor populations in Rajasthan and Uttar Pradesh as a part of IPE Global Project PAHAL (Partnerships for Affordable Healthcare Access and Longevity). Findings from the study reflect that the unmet need of family planning among the married women in the selected states was more than $15 \%$. Women having three children reported the highest use of modern contraceptive methods and the lowest was found among the women having no child. Use of modern contraception was low among the women who were the head of the households. Working women, women belonging to richest wealth quintile, women whose husbands reported to be working and women from male headed households were less likely to have unmet need for family planning. The findings of the present study indicate a remarkably low prevalence of modern contraceptive use indicating considerable high unmet need. This can be a concern and special emphasis of the policy makers should be on this since it is well researched that modern contraceptive use and addressing unmet need are of overriding importance in reducing pregnancy related morbidity, preventing unintended pregnancies that lead to abortion and will gradually improve reproductive well-being among women.
\end{abstract}

\section{Keywords}

Unmet Need, Modern Contraceptives, Urban Poor, Family Planning 


\section{Introduction}

\subsection{Background}

For decades, information about unmet need for contraception has enabled health advocates and professionals, policymakers and funding agencies to identify the investments needed in family planning programs in developing countries (Sedgh et al., 2016). The unmet need for family planning is a crucial indicator for assessing the future demand for family planning services/supplies. Casterline \& Silding (2000) also found that unmet need for family planning has been a core concept in international population discourse for several decades. Unmet need refers to fecund women who either wish to postpone the next birth (spacers) or who wish to stop childbearing (limiters) but are not using a contraceptive method (Lata et al., 2012; Shifa, 2014). Many women who are sexually active would prefer to avoid becoming pregnant but are not using any method of contraception. These women are considered to have an unmet need for family planning (Bhattacharya et al., 2006). "Unmet need for family planning", which refers to the condition of wanting to avoid or postpone childbearing but not using any method of contraception, has been a core concept in international population for many decades (Casterline \& Sinding, 2000; Freedman, 1987). Unmet need for family planning points to the gap between women's reproductive desire to avoid pregnancy and contraceptive behavior. Unmet need for family planning refers to a discrepancy between expressed fertility preferences and practice of contraception - i.e., the failure to translate a stated desire to avoid pregnancy into pregnancy-prevention behavior (Darroch \& Singh, 2013).

\subsection{Conceptualization}

The concept of unmet need was first demonstrated based on the data collected in surveys in 1960s that inquired about women's knowledge of, attitudes towards and practice of birth control, as well as family-size preference. The results from these surveys indicated that a substantial portion of women who wanted to stop childbearing were not practicing contraception (Bongaarts \& Bruce, 1995). Despite recent progress in decreasing its prevalence, it is estimated that 222 million women in low- and middle-income countries have an unmet need for modern contraception (Darroch \& Singh, 2013). A high level of unmet need for contraception persists among currently married women in South Asia. At least 1 in 5 currently married women in the countries surveyed want to stop or delay childbearing, but are not using contraception (Rossi-Espagnet, 1984). The currently married young women (15 - 24 years) in India form one of the largest groups with an unmet need for reproductive health services (Pachauri \& Santhya, 2002). Brown et al. (2014) found number of living sons, child loss, rural urban residence, education, media exposure and accessibility of family planning facility plays significant role in unmet need of Uttar Pradesh.

Using self-reported reasons, studies in the 1990s identified lack of knowledge, fear of side effects and social disapproval by family as the major obstacles to 
contraceptive use in many countries that participated in the first round of DHS (Bongaarts \& Bruce, 1995) and lack of information, opposition to contraception, ambivalence about future childbearing emerged as main causes of unmet need in the second DHS round (Westoff \& Bankole, 1995).

\subsection{Causes and Implications of Unmet Need}

The existing research literature also suggests that understanding the causes of unmet need for family planning requires better appreciation of the complexity of fertility desires (Machiyama et al., 2017). More recently, Sedgh and Hussain (2014) assessed women's direct responses on reasons for non-use of modern contraception using recent DHSs from 51 developing countries, and showed fear of side effects/adverse health risk and infrequent sex as the dominant reasons for contraceptive non-use.

With relevant data on those countries, Sedgh et al. (2016) also found four key reasons cited by married women in those countries for not using contraception leading to unmet need. They were side effects or health risks of contraceptive methods; no sexual interaction or infrequent sex, they or others close to them oppose contraception; and their belief that they do not need or should not use contraception if they are breastfeeding, they haven't resumed menstruation after a birth (i.e., they have postpartum amenorrhea), or both. Machiyama et al., (2017) concluded that if dissatisfaction to a specific method is a reason for discontinuation, family planning programmes need to refine their focus on responding to women's demand for more suitable satisfactory methods.

Unmet need for family planning has implication for short birth intervals and higher fertility levels, particularly through the mechanisms of too many births and too frequent births. Evidence from Nigeria shows a significant association between under five-mortality and unmet need for family planning along with far ranging consequences (Adedini, 2015).

\subsection{Unmet Need: A Concern}

Many developing countries consider rapid population growth a major constraint to development and have adopted population policies designed to reduce this rate of growth. Because of this, reducing unmet need for family planning has been a central aim for reproductive health policy, programmes and research for decades (Machiyama et al., 2017).

It is always believed that modern contraceptive use is an important public health intervention and a cost-effective strategy to reduce maternal mortality, avert unintended pregnancies and to control population explosion, especially in developing countries (Beson \& Adomah-Afari, 2018). Despite these benefits, there are reports of low usage among reproductive-aged women in most developing countries. The use of modern methods of contraception dramatically reduces the chance of an unplanned births as well as abortions (Darroch et al., 2016). 
It is generally perceived that the increasing number of health service providers i.e. both public and private in urban areas, would eventually cater to the family planning needs and demands of urban population (Mathews et al., 2010). However, rapid urbanization coupled with relentless growth of slum populations created acute disparity within cities and made this supposition a distant dream in the developing world (Rossi-Espagnet, 1984). Despite living in the urban settings, urban poor population are equally disadvantaged as their rural counterparts due to over-crowding, high demand for limited resources, increased cost of services in urban settings, and lack of access to clean water and sanitation (Montgomery, 2009; Mathews et al., 2010). Moreover, these urban poor populations are often forced to use either public health facilities or seek care at unregulated, often low quality private health services that offer care at a reduced price (Mathews et al., 2010).

Developing world governments struggle with reducing poverty through implementing programs that address the Millennium Development Goals (MDG), attention had been paid to the role of family planning (family planning) programs in promoting women and men's reproductive rights and ensuring universal access to high quality voluntary family planning services for the attainment of these MDGs by 2015. A recent family planning 2020 initiative during the London Summit was launched across 60 developing countries in 2012 to coordinate global efforts to expand the access to family planning services. As a part of this initiative, India is committed to cover 48 million additional women which would mean reaching contraceptive prevalence rate (CPR) of $63.7 \%$ by the year 2020 (Brown et al., 2014; Achyut et al., 2016).

\subsection{Unmet Need of Family Planning in India}

Consideration of the family planning and reproductive health needs of women, men, and couples in urban India is increasingly important, given the rapid growth in the number of people living in urban poor settings throughout India. According to NFHS-4, 13\% of married women have unmet need for family planning almost same as NFHS-3 (14\%). In India, the prevalence of contraceptive use among women in the reproductive age is $53.5 \%$ (NFHS-4). Few studies showed that women living in slums were significantly less likely to use modern family planning than women outside slums.

Not many available published community based studies have given district-wise unmet need for family planning for the urban poor population in two states. There are national level surveys which provide the state-wise estimates but they are not being frequently conducted. So the present study was undertaken to fulfill the existing gaps in evidence, under IPE Global Project PAHAL (Partnerships for Affordable Healthcare Access and Longevity) in India, with an objective of determining the extent and pattern of utilization of family planning services and identifying the determinants of unmet need of family planning methods in the six districts of Rajasthan and Uttar Pradesh. 


\section{Methodology}

The data for this paper is derived from a baseline cross sectional survey conducted by IPE Global, New Delhi and School of Public Health, PGIMER, Chandigarh. The study was conducted in two states of Rajasthan and Uttar Pradesh. The intervention districts were Jaipur and Bharatpur in Rajasthan, and Lucknow and Allahabad in Uttar Pradesh. Alwar in Rajasthan and Kanpur in Uttar Pradesh were selected as control districts. The finding of this paper is based on the subsample analysis of the larger data collected for the baseline survey.

\subsection{Sample}

Since the states fared differently in terms of key coverage indicators, an expected coverage of $50 \%$ was utilized for calculations to yield maximum sample size. With an absolute error of 5\%, 95\% Confidence Interval and design effect size of $1.5 \%$ and $10 \%$ or refusal and non-response, the total sample size came out to be 2400 to compensate for any non/partial response during the survey.

The study was conducted among the urban poor population who were earning between 3 - 9 USD per day. The eligible respondents for this study were currently married women aged between 18 - 49 years. In the selected districts, 5 urban wards were selected and in each ward 2 Census Enumeration Block (CEB) were selected. Household selection was done applying systematic random sampling using right hand rule till the time the desired sample was reached.

\subsection{Data Collection}

A pre-designed and pre-tested semi structured questionnaire was designed for respondents of various age groups for data collection through the community based survey.

The data collection was done using Computer Assisted Personal Interview (CAPI) using a tablet. After obtaining written informed consent from the eligible women, a structured questionnaire was used to elicit information from the respondents. These were designed to investigate unmet need for family planning, total demand for family planning and demand satisfied along with factors affecting these indicators.

Quality control was undertaken by field supervisors, who revisited 5\% of sampled households to check accuracy of data. Any discordance was resolved through discussion and re-visiting the household.

\subsection{Data Analysis}

The data was analyzed using IBM SPSS ver. 21. Bivariate analysis was conducted to examine the association of contraception prevalence and total unmet need for family planning with socio-demographic variables. We used different models of logistic regression to identify significant associations between unmet need for family planning and use of modern contraceptives with the explanatory variables, while controlling for potential confounders in each model. The depen- 
dent variables were use of modern contraception and total unmet need for spacing and limiting for family planning and the independent variables were age, state/district, religion, social group, education, occupation, and wealth quin tiles (Table 1).

Wealth status was assessed using household consumption expenditure. The adjusted odds ratio was reported as a measure of association along with the $95 \%$ confidence limits and p-value.

\subsection{Measures}

The definitions of the few important indicators used in this study have been discussed below:

Unmet need of family planning: Unmet need for family planning is defined as the percentage of women of reproductive age, either married or in a union, who have an unmet need for family planning. Women with unmet need are those who want to stop or delay childbearing but are not using any method of contraception (Measure Evaluation, n.d.; NFHS-4, 2017; WHO, 2015).

Unmet need of spacing: Women with an unmet need for spacing are those who desire to postpone their next birth by a specified length of time (for example, for at least two years from the date of a survey) and who do not currently use a contraceptive method (Measure Evaluation, n.d.; NFHS-4, 2017).

Unmet need of limiting: Women with an unmet need for limiting are those who desire no additional children and who do not currently use a contraceptive method (Measure Evaluation, n.d.; NFHS-4, 2017).

Total demand of family planning: The indicator follows from the breakdown of total demand for FP services into two components: "met demand" and "unmet demand" (or "unmet need") (WHO, 2015).

Demand satisfied: Total demand for family planning is defined as the sum of the number of women of reproductive age (15 - 49 years) who are married or in a union and who are currently using, or whose sexual partner is currently using, at least one contraceptive method, and the unmet need for family planning. Percentage of women of reproductive age (15 - 49 years old) who have their demand for family planning satisfied with modern methods (WHO, 2015; Measure Evaluation, n.d.).

Table 1. Variables used in the study make variables-plural.

\begin{tabular}{crc}
\hline \multicolumn{1}{c}{ Dependent variables } & Independent variables \\
\hline Use of modern contraception & Age \\
Total unmet need for spacing for family planning & $\begin{array}{c}\text { Unmet need of } \\
\text { family planning }\end{array}$ & State/District \\
Total unmet need of limiting for family planning & Religion \\
& Social group \\
& Education \\
\end{tabular}




\subsection{Ethical Clearance}

Ethical clearance for the study was obtained from Institute Ethics Committee of PGIMER. A written informed consent for participation was also obtained from respondents during the household survey.

\section{Results}

\subsection{Socio-Economic and Demographic Characteristics of the Respondents}

The survey sample included a total of 2229 currently married women in the age group of 15 - 49 years (Table 2). The mean age of women at marriage and at first pregnancy was around 18 years (Mean $\pm S D=18.6 \pm 2.21$ ) and 20 years (Mean \pm $\mathrm{SD}=20.1 \pm 2.67)$ respectively. Majority of the women were in the age group of 25 - 34 years and around 13\% of the women reported themselves as being heads of households. Majority of the households covered under the survey reported themselves as Hindu (84\%). Around 58\% of the overall sample belonged to Scheduled Castes/Scheduled Tribes while $28 \%$ to Other Backward Classes. Only $14 \%$ of the surveyed respondents belonged to General caste. One-third of the women's husbands had never been to school, and $31 \%$ of the husbands had completed 12 or more years of schooling. Majority of the husbands were wage laborers or self-employed. A little over a quarter of the respondents had parity of 2 and another $27 \%$ had parity of 4 or more. Close to half of the surveyed women were illiterate and one-fifth women had 9 or more years of education. A majority $(86 \%)$ of them were unemployed and a quarter of them belonged to the richest wealth quintile (26\%) while one third belonged to the poor/poorest wealth quintile.

Table 2. Socio-economic and demographic characteristics of the respondents.

\begin{tabular}{lccc}
\hline & & Frequency & Percent \\
\hline Average age at the time of marriage (Mean \pm SD) & & $18.6 \pm 2.21$ \\
\hline Average age at the time of first pregnancy (Mean \pm SD) & $15-24$ & 522 & 23.4 \\
\hline Age of the women & $25-34$ & 963 & 43.2 \\
& $35-49$ & 744 & 33.4 \\
Total & Male & 2229 & 100.0 \\
& Female & 1931 & 86.6 \\
Teligion & Total & 298 & 13.4 \\
& Hindu & 2229 & 100.0
\end{tabular}




\section{Continued}

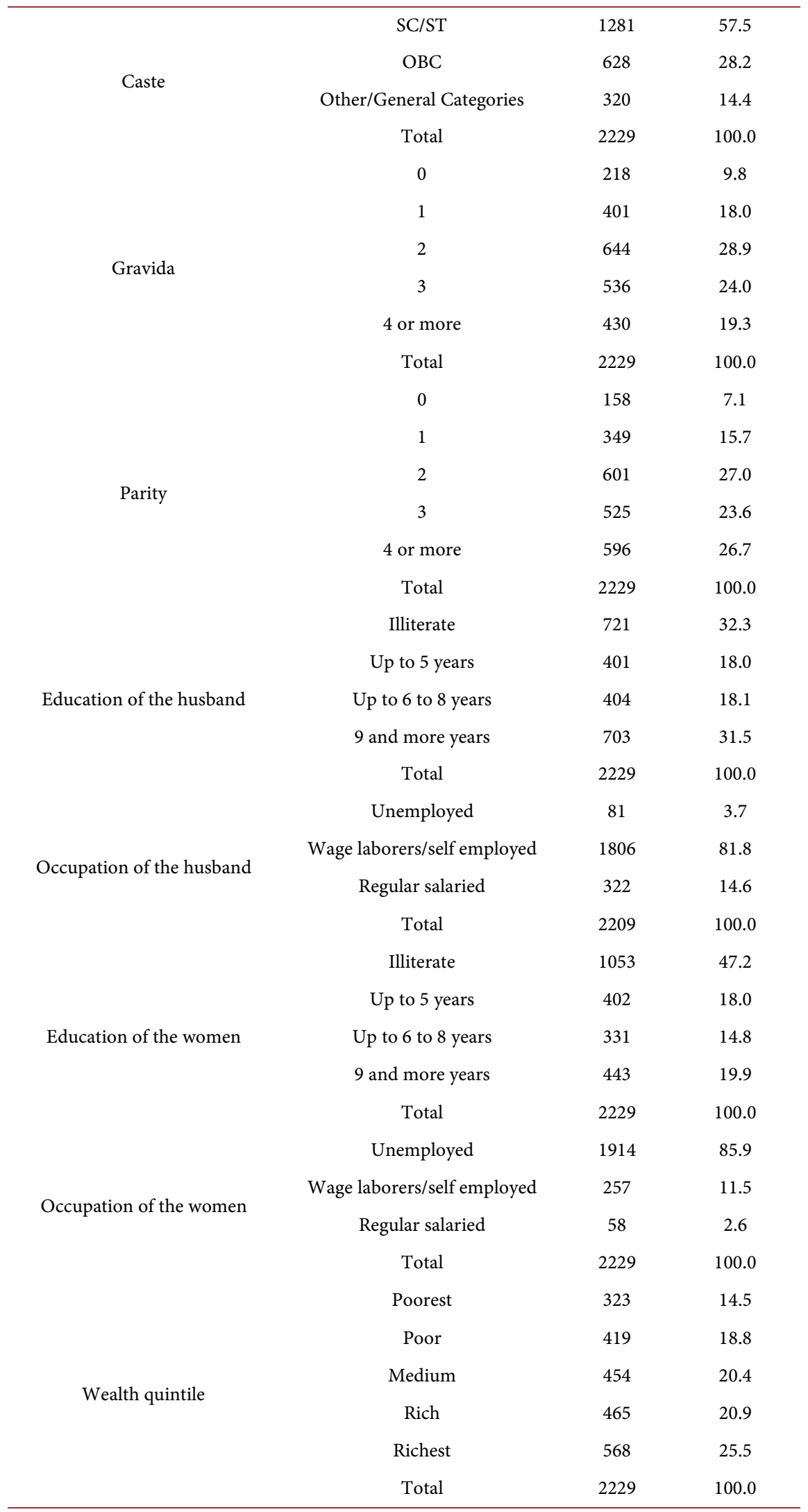

Wealth quintile based on monthly expenditure. 


\subsection{Socio-Economic and Demographic Determinants of the Use of Modern Contraception and Unmet Need}

Table 3 presents socio-economic and demographic factors influencing the use of modern contraception, unmet need for family planning and demand for family planning. It also covers demand satisfied by the respondents. A little over half of the women used modern contraception and $16 \%$ had unmet need of contraception. The unmet need for limiting was $10 \%$ while $5.4 \%$ women had unmet need for spacing. The total demand for family planning among the surveyed respondents was $67 \%$ and among them more than three-fourths of the women had the demand satisfied. The use of modern contraceptives was 53\% among Hindu women as compared to $42 \%$ by Muslim respondents. There was not much difference observed by religion when unmet need was considered. The unmet need among Muslim women was $18 \%$ as compared to $15 \%$ among Hindu women. Also, 78\% Hindu women had their demand satisfied for contraception as compared to $70 \%$ Muslim women.

Not much difference was reported among the different social groups regarding unmet need or modern contraceptive prevalence.

Table 3. Socio-economic and demographic determinants of the modern contraceptive use and unmet need for family planning among the respondents.

\begin{tabular}{|c|c|c|c|c|c|c|c|}
\hline & & $\begin{array}{c}\text { Modern } \\
\text { contraceptive } \\
\text { prevalence rate } \\
(\mathrm{MCPR})\end{array}$ & $\begin{array}{l}\text { Unmet need } \\
\text { for limiting }\end{array}$ & $\begin{array}{l}\text { Unmet } \\
\text { need for } \\
\text { spacing }\end{array}$ & $\begin{array}{c}\text { Total } \\
\text { unmet } \\
\text { need }\end{array}$ & $\begin{array}{l}\text { Total demand } \\
\text { for family } \\
\text { planning }\end{array}$ & $\begin{array}{c}\text { Percentage } \\
\text { of demand } \\
\text { satisfied }\end{array}$ \\
\hline \multirow{4}{*}{ Religion } & Hindu & 52.7 & 10.1 & 5.2 & 15.3 & 68.0 & 0.78 \\
\hline & Muslim & 41.7 & 11.1 & 6.5 & 17.6 & 59.3 & 0.70 \\
\hline & Others & 60.4 & 10.4 & 6.3 & 16.7 & 77.1 & 0.78 \\
\hline & Total & 51.3 & 10.3 & 5.4 & 15.7 & 67.0 & 0.77 \\
\hline \multirow{4}{*}{ Caste } & $\mathrm{SC} / \mathrm{ST}$ & 51.4 & 9.1 & 6.4 & 15.5 & 66.9 & 0.77 \\
\hline & $\mathrm{OBC}$ & 51.8 & 10.8 & 4.3 & 15.1 & 66.9 & 0.77 \\
\hline & Other/General Categories & 50.3 & 14.1 & 3.8 & 17.9 & 68.2 & 0.74 \\
\hline & Total & 51.3 & 10.3 & 5.4 & 15.7 & 67.0 & 0.77 \\
\hline \multirow{3}{*}{$\begin{array}{l}\text { Head of the } \\
\text { household }\end{array}$} & Male & 52.1 & 9.4 & 6.2 & 15.6 & 67.7 & 0.77 \\
\hline & Female & 46.0 & 16.1 & 0.3 & 16.4 & 62.4 & 0.74 \\
\hline & Total & 51.3 & 10.3 & 5.4 & 15.7 & 67.0 & 0.77 \\
\hline \multirow{6}{*}{$\begin{array}{c}\text { Gravida } \\
\text { (no. of living } \\
\text { children) }\end{array}$} & 0 & 3.7 & 3.7 & 2.8 & 6.5 & 10.2 & 0.36 \\
\hline & 1 & 32.7 & 12.5 & 15.5 & 28.0 & 60.7 & 0.54 \\
\hline & 2 & 60.6 & 9.6 & 5.4 & 15.0 & 75.6 & 0.80 \\
\hline & 3 & 65.9 & 11.4 & 2.2 & 13.6 & 79.5 & 0.83 \\
\hline & 4 or more & 60.9 & 11.2 & 1.4 & 12.6 & 73.5 & 0.83 \\
\hline & Total & 51.3 & 10.3 & 5.4 & 15.7 & 67.0 & 0.77 \\
\hline
\end{tabular}




\section{Continued}

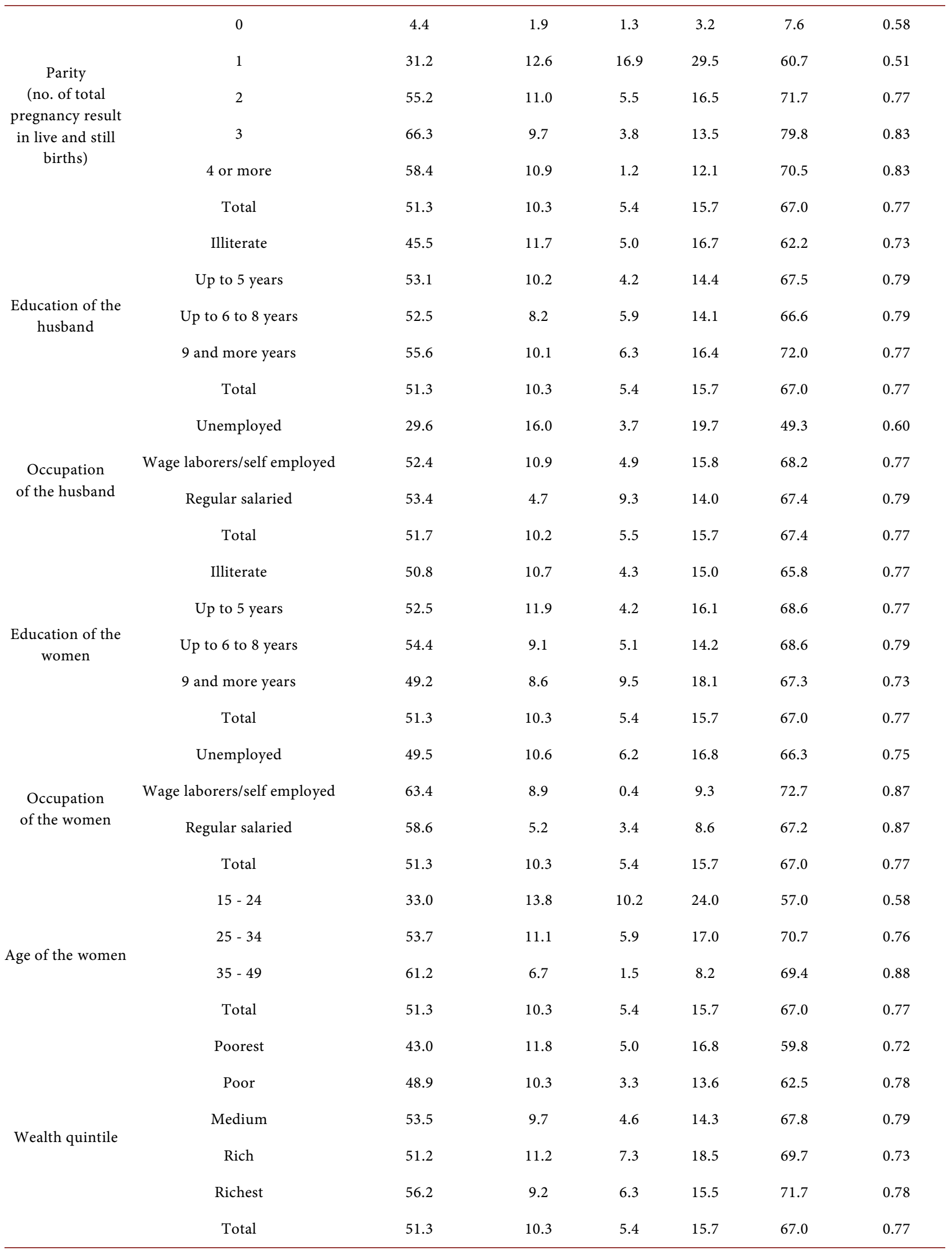


Use of modern contraception was found to be lower among the female headed households (46\%) than the male headed households (52\%). The unmet need for family planning was also slightly more (16.4\%) among the female headed households.

Women having three children reported the highest use of modern contraceptive methods (66\%) and the lowest was found among the women having no child (3.7\%). Similarly, women with parity of 3 reported highest use of modern contraception (66\%) whereas women with a parity of one had highest unmet need (30\%). Similar pattern was observed among women when unmet need for limiting and unmet need for spacing was considered separately.

Results suggest that with increasing education of the husbands, the modern contraceptive prevalence rate also increased. About $46 \%$ women whose husbands were illiterate used modern contraceptives as compared to $56 \%$ women whose husbands had 9 or more years of education. Occupation of the husband played an important role in determining the use of modern contraceptives among the women. Less than one third of the respondents whose husbands were unemployed used modern contraceptives as compared to more than half women whose husbands were wage earners, self-employed or regular salaried. Likewise, the total unmet need was also less (14\%) among the women whose husbands were regular salaried as compared to one-fifth women whose husbands were unemployed. Similarly, demand satisfied was also high (79\%) among the women whose husbands were regular salaried as compared to $60 \%$ women whose husbands were unemployed. Similar results were observed when occupation of the women was considered. Education of the women did not have much influence on the use of modern contraceptive and unmet need or demand satisfied. Results also indicated that use of modern contraceptive was increasing with increasing age of the women and unmet need was decreasing. Women aged 15 - 24 had the highest unmet need for family planning (24\%) as compared to women aged 25 34 years $(17 \%)$ and 35 - 49 years $(8.2 \%)$. Similar pattern was also observed for unmet need for limiting and spacing.

Wealth also influenced unmet need for family planning. Married women from the rich quintiles had the highest unmet need for family planning (18.5\%) while the poor women had the lowest unmet need (13.6\%).

\subsection{District-Wise Use of Modern Contraceptive and Unmet Need}

District wise use of modern contraceptive and unmet need for family planning for Rajasthan and Uttar Pradesh is shown in Table 4. The overall use among the women as reported in the state of Rajasthan was higher (56.4\%; CI: UL53.4; LL59.5) than the state of Uttar Pradesh (47\%; CI: UL44.1, LL49.8). The women in Jaipur district had the highest use (70\%) followed by those in Allahabad district (56\%). The lowest use was reported among the women in the Bharatpur district (40.2\%) and they also reported high unmet need for family planning (18\%). The unmet need for limiting and spacing was $14 \%$ and $4.7 \%$ respectively. 
Table 4. District-wise use of modern contraceptive and unmet need for family planning among the respondents.

\begin{tabular}{ccccc}
\hline & $\begin{array}{c}\text { Use of modern } \\
\text { contraceptive, 95\% } \\
\text { CI (LL, UL) }\end{array}$ & $\begin{array}{c}\text { Total unmet need for family } \\
\text { planning average, 95\% } \\
\text { CI (LL, UL) }\end{array}$ & $\begin{array}{c}\text { Unmet need for limiting } \\
\text { average, 95\% } \\
\text { CI (LL, UL) }\end{array}$ & $\begin{array}{c}\text { Unmet need for } \\
\text { spacing average, } \\
\text { 95\% CI (LL, UL) }\end{array}$ \\
\hline Alwar & $52.5(45.9,59.1)$ & Rajasthan & $4.6(1.8,7.3)$ \\
Bharatpur & $40.2(35,45.5)$ & $15.5(10.7,20.3)$ & $11(6.8,15.1)$ & $4.7(2.5,7.0)$ \\
Jaipur & $69.9(65.7,74.0)$ & $18.3(14.2,22.5)$ & $13.6(10,17.3)$ & $4.5(2.6,6.3)$ \\
Overall & $56.4(53.4,59.5)$ & $13(9.9,16.0)$ & $8.7(6.2,11.3)$ & $4.6(3.3,5.8)$ \\
Allahabad & & $15.3(13.1,17.5)$ & $10.8(8.9,12.7)$ & $4.1(1.3,6.8)$ \\
Kanpur & $55.8(48.9,62.8)$ & Uttar Pradesh & $10.7(6.4,15.0)$ & $12.3(9.5,15.2)$ \\
Lucknow & $43.1(38.8,47.3)$ & $14.7(9.8,19.7)$ & $5.3(3.3,7.2)$ & $0.6(0.3,1.3)$ \\
Overall & $47.5(43.1,51.9)$ & $17.6(14.3,20.9)$ & $14.2(11.1,17.3)$ & $6.8(4.8,7.5)$ \\
\hline
\end{tabular}

\subsection{Use of Different Family Planning Methods}

Table 5 presents the use of different family planning methods among the respondents. Overall the most preferred contraceptive method in both the states was condoms (32\%) followed by female sterilization (26\%) and pills (23\%). As high as $66 \%$ women in the Alwar district preferred female sterilization as a method of family planning. On the other hand, female sterilization in Allahabad was only $2.3 \%$. Female sterilisation as a method of family planning was also low in the districts of and Kanpur (11\%) and Bharatpur (16\%). Whereas, the use of condoms was specifically high in the districts of Kanpur (50\%), Lucknow (49\%) and Allahabad (41\%) and low in the districts of Rajasthan. Use of condom, pills, IUD and male sterilization was the lowest in the district of Alwar. The use of traditional methods was highest in the Bharatpur (28\%) followed by Alwar (12\%) and almost no woman in the Jaipur and Lucknow district used traditional methods. More than one third of the women in the Allahabad (36\%) and Jaipur (34\%) were using the contraceptive pills as a method of family planning. It was also found that use of IUD was highest in Jaipur (18\%) followed by Allahabad (13\%). Male sterilization was not prevalent at significant levels in both the states.

\subsection{Factors Associated with the Use of Modern Contraception and the Unmet Need}

Table 6 presents factors associated with the use of modern contraception and the unmet need among the women using a Pearson's chi-square test with a $p$-value $<0.05$. Variables with $p<0.05$ were selected to be included in the multivariate analysis.

It was observed that religion, head of the household, gravida, parity, education level of the husband, occupation of the husband and women, age of the women and wealth quintile made a significant difference to the use of modern contraceptive methods $(p<0.01)$. Statistical significant differences were also observed among the gravida, parity, women's education and age of the women with the unmet need for family planning. 
Table 5. Use of different family planning methods among the respondents.

\begin{tabular}{ccccccccc}
\hline & & Female sterilization & Male sterilization & IUD & Pills & Injectable & Condom & Traditional method \\
\hline \multirow{4}{*}{ Rajasthan } & Alwar & 66.2 & 0.0 & 2.3 & 5.4 & 0.8 & 13.8 & 11.5 \\
& Bharatpur & 16.0 & 1.6 & 2.7 & 26.1 & 1.6 & 24.5 & 27.7 \\
& Jaipur & 33.4 & 0.0 & 18.2 & 34.0 & 0.0 & 14.3 & 0.0 \\
& Total & 34.9 & 0.5 & 10.5 & 26.0 & 0.6 & 17.2 & 10.4 \\
\multirow{3}{*}{ Uttar } & Allahabad & 2.6 & 0.0 & 13.0 & 35.7 & 3.5 & 40.9 & 4.3 \\
Pradesh & Kanpur & 11.2 & 0.4 & 11.2 & 14.9 & 2.9 & 50.4 & 9.1 \\
& Lucknow & 26.8 & 0.0 & 3.0 & 19.1 & 2.1 & 48.5 & 0.4 \\
Total & Total & 15.7 & 0.2 & 8.3 & 20.6 & 2.7 & 47.8 & 4.7 \\
\hline
\end{tabular}

Table 6. Determinants of use of modern contraception and unmet need for family planning among the respondents.

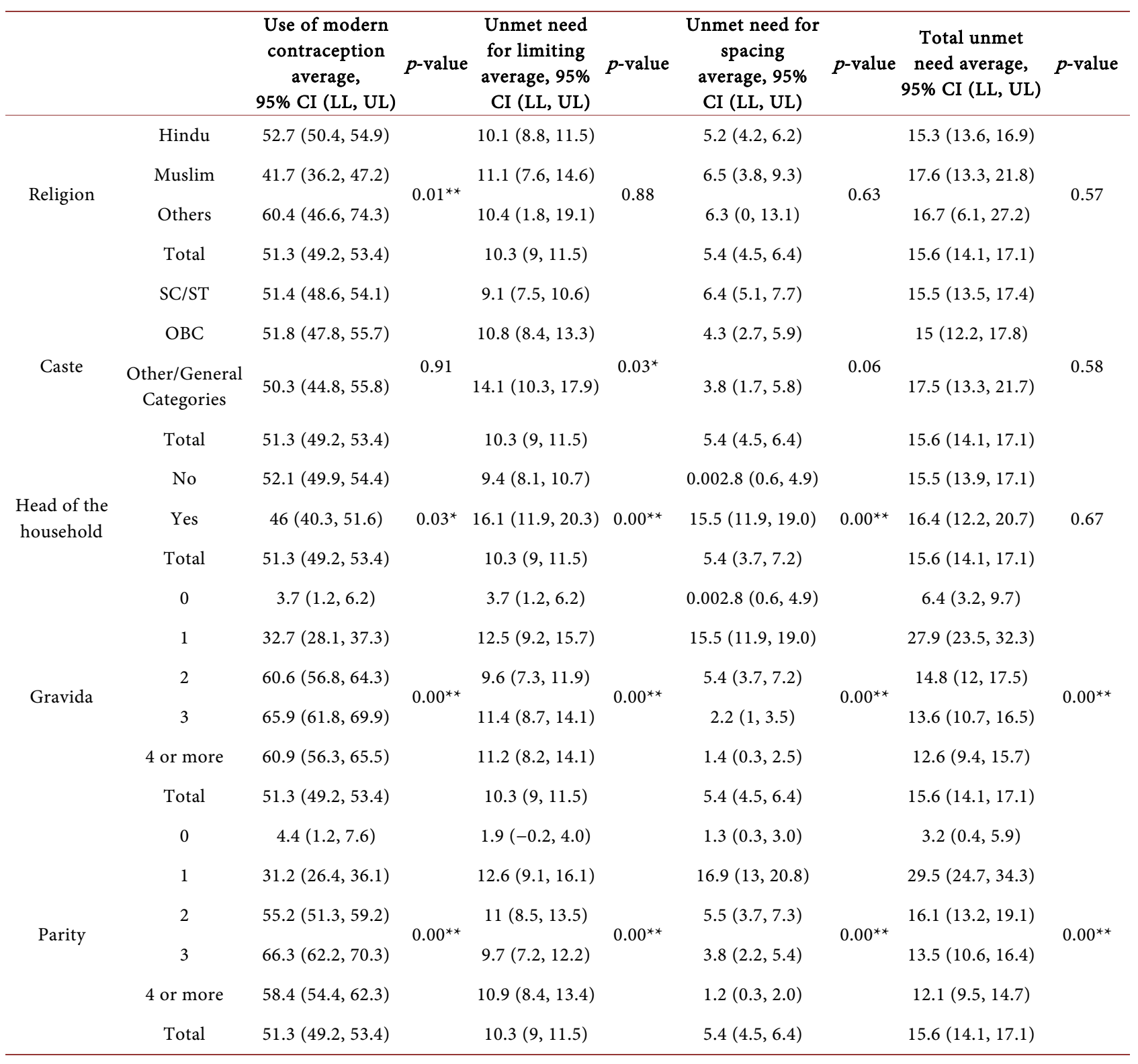




\section{Continued}

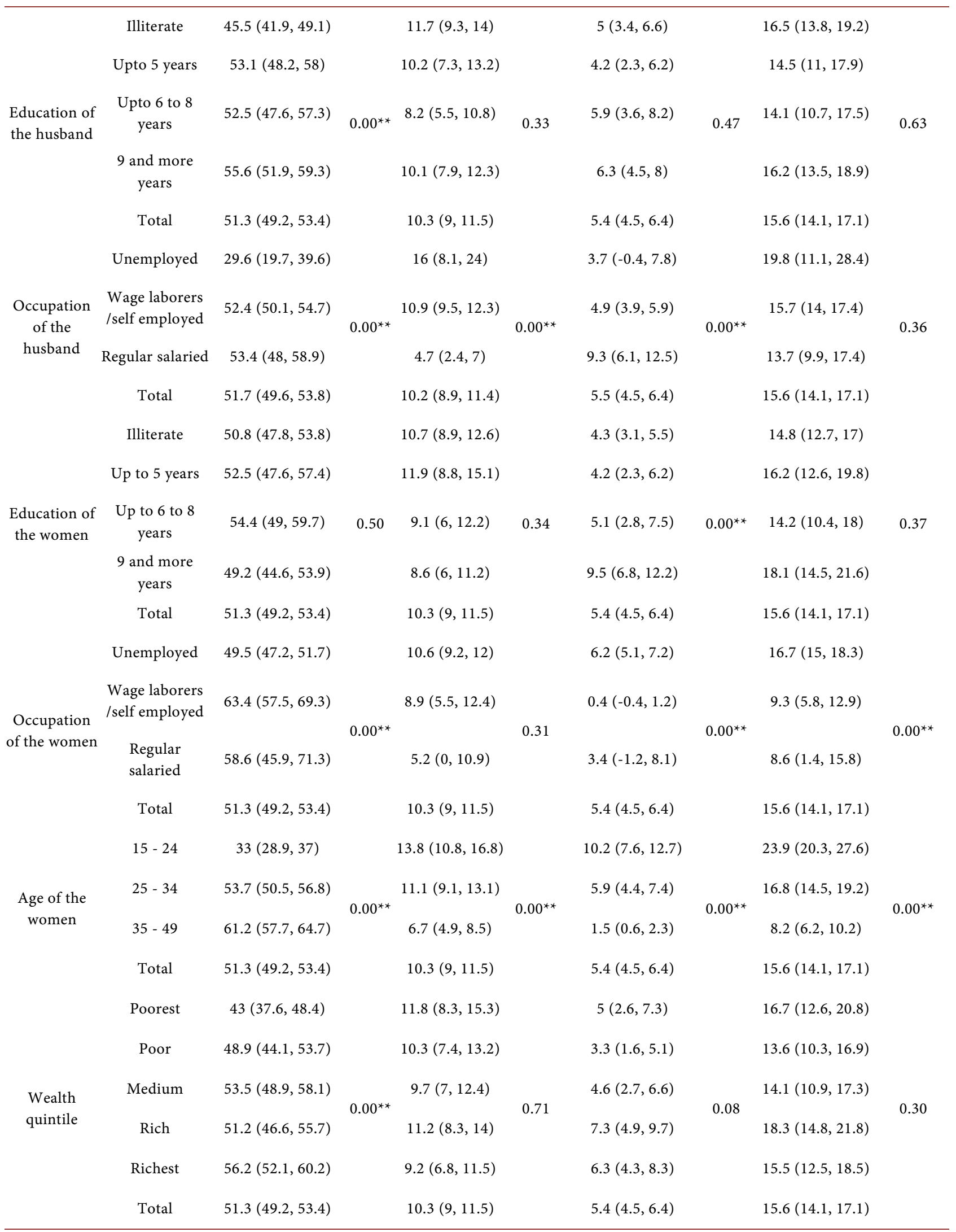

** Significant at 0.01 and ${ }^{*}$ Significant at 0.05 levels. 


\subsection{Regression Analysis}

Results of the multivariate regression analysis have been presented in Table 7. Findings suggest that women aged $25-35$ and $35-49$ were 1.38 times [OR = $1.38(1.05,1.81)]$ and 1.48 times $[\mathrm{OR}=1.48(1.08,2.03)]$ more likely to use modern contraceptives. They were also $34 \%[\mathrm{OR}=0.66(0.49,0.9)]$ and $72 \%$ $[\mathrm{OR}=0.28(0.19,0.43)]$ less likely to have unmet need of contraception with reference to women aged 15 - 24. Women having less children were more likely to use modern contraceptives and were more likely to have unmet need for spacing as compared to those having four children or more. Working women were $40 \%$ less likely $[\mathrm{OR}=0.61(0.4-0.92)]$ to have unmet need for family planning but 1.6 times $[\mathrm{OR}=1.55(1.17,2.05)]$ more likely to use modern contraceptives as compared to non-working women. Women belonging to richest wealth quintile were 1.5 times more likely $[\mathrm{OR}=1.52(1.1,2.1)]$ to use modern contraceptives as compared to the women belonging to poorest wealth quintile. Hindu women were 1.3 times more likely $[\mathrm{OR}=1.32(1.02,1.7)]$ to use modern contraceptives than Muslim women. Women who were not household heads were 1.3 times $[\mathrm{OR}=1.34(1.01,1.77)]$ more likely to use modern contraceptives. Furthermore, results indicate that the women whose husbands were educated were more likely to use modern contraceptives. Working women were $40 \%$ $[\mathrm{OR}=0.61(0.4,0.92)]$ less likely to have unmet need of contraception and were $75 \%[\mathrm{OR}=0.25(0.08,0.82)]$ less likely to have unmet need of limiting.

Women whose husbands reported to be working were almost 2 times [OR = $1.95(01.13,3.36)]$ more likely to use modern contraceptives and were $60 \%$ less likely $[\mathrm{OR}=0.38(0.2,0.74)]$ have unmet need of limiting.

\section{Discussion}

This study was conducted with an objective of determining the extent and pattern of utilization of family planning services, and the determinants of unmet need of family planning methods in the six districts of Rajasthan and Uttar Pradesh. Data collection was done among 2229 currently married women in the age group of 15 - 49 years to accomplish the study objective.

\subsection{State-Level Findings}

Findings from the study reflect that the unmet need of family planning among married women was $15.3 \%$ in Rajasthan and 15.9 in Uttar Pradesh. This is corroborated by similar findings under NFHS-4, reflecting an unmet need of family planning in Rajasthan at $12.1 \%$ and $13.4 \%$ in urban UP. Another study focusing on urban Rajasthan found out that the unmet need was $41 \%$ among the urban women which is significantly higher than our study findings. Our study findings also indicate that more than half of the women used modern contraceptives in Rajasthan while this percentage was little lower in Uttar Pradesh. This finding is consistent with the finding of NFHS-4 (2015-16) that 58\% or women in urban Rajasthan and $40 \%$ women in urban Uttar Pradesh uses modern contraceptive. 
Table 7. Result of the Logistics regression analysis showing odds ratio with 95\% CI for use of modern contraception and unmet need for family planning among the respondents.

\begin{tabular}{|c|c|c|c|c|c|}
\hline & & $\begin{array}{l}\text { Use of modern } \\
\text { contraception } \\
\text { OR, 95\% CI } \\
(L L, U L)\end{array}$ & $\begin{array}{l}\text { Unmet need for } \\
\text { limiting } \\
\text { OR, 95\% CI } \\
\text { (LL, UL) }\end{array}$ & $\begin{array}{l}\text { Unmet need for } \\
\text { spacing } \\
\text { OR, 95\% CI } \\
\text { (LL, UL) }\end{array}$ & $\begin{array}{c}\text { Total unmet need } \\
\text { OR, 95\% CI } \\
(\mathrm{LL}, \mathrm{UL})\end{array}$ \\
\hline \multirow{2}{*}{ Religion } & Hindu & $1.32^{\star}(1.02,1.7)$ & & & \\
\hline & Muslim/other (RF) & - & & & \\
\hline \multirow{3}{*}{ Caste } & $\mathrm{SC} / \mathrm{ST}$ & & $1.18(0.85,1.64)$ & & \\
\hline & $\mathrm{OBC}$ & & $1.55^{\star}(1.05,2.28)$ & & \\
\hline & Other/General Categories & & - & & \\
\hline \multirow{2}{*}{$\begin{array}{l}\text { Head of the } \\
\text { household }\end{array}$} & No & $1.34^{*}(1.01,1.77)$ & $0.64^{\star}(0.44,0.94)$ & $17.9^{* *}(2.47,130.33)$ & \\
\hline & Yes (RF) & - & - & - & \\
\hline \multirow{5}{*}{ Gravida } & 0 & $0.004^{\star *}(0.001,0.04)$ & $0.28(0.07,1.05)$ & $0.33(0.05,2.2)$ & $0.24^{\star *}(0.08,0.69)$ \\
\hline & 1 & $0.14^{* *}(0.07,0.25)$ & $0.44(0.17,1.14)$ & $1.15(0.23,5.6)$ & $0.64(0.29,1.4)$ \\
\hline & 2 & $0.61^{\star}(0.38,0.96)$ & $0.41^{\star}(0.18,0.93)$ & $0.87(0.2,3.83)$ & $0.55(0.28,1.09)$ \\
\hline & 3 & $0.78(0.54,1.13)$ & $1.07(0.6,1.9)$ & $0.38(0.09,1.7)$ & $0.85(0.49,1.47)$ \\
\hline & 4 or more $(\mathrm{RF})$ & - & - & - & - \\
\hline \multirow{5}{*}{ Parity } & 0 & $7.01(0.77,63.8)$ & $0.15(0.02,1.07)$ & $1.33(0.13,13.25)$ & $0.43(0.11,1.71)$ \\
\hline & 1 & $2.91^{\star \star}(1.54,5.52)$ & $1.17(0.43,3.15)$ & $7.13^{\star}(1.54,32.99)$ & $2.29 *(1.04,5.04)$ \\
\hline & 2 & $1.6^{\star}(1.01,2.51)$ & $1.42(0.64,3.16)$ & $2.56(0.63,10.49)$ & $1.33(0.69,2.54)$ \\
\hline & 3 & $1.7^{\star \star}(1.19,2.42)$ & $0.75(0.42,1.31)$ & $3.96^{*}(1.04,15.18)$ & $1(0.6,1.68)$ \\
\hline & 4 or more $(\mathrm{RF})$ & - & - & - & - \\
\hline \multirow{4}{*}{$\begin{array}{l}\text { Education of } \\
\text { the husband }\end{array}$} & Illiterate (RF) & - & & & \\
\hline & Up to 5 years & $1.39^{\star}(1.06,1.83)$ & & & \\
\hline & Up to 6 to 8 years & $1.37^{\star}(1.03,1.81)$ & & & \\
\hline & 9 and more years & $1.64^{* *}(1.27,2.12)$ & & & \\
\hline \multirow{4}{*}{$\begin{array}{l}\text { Education of } \\
\text { the women }\end{array}$} & Illiterate & & & - & \\
\hline & Up to 5 years & & & $0.65(0.36,1.18)$ & \\
\hline & Up to 6 to 8 years & & & $0.81(0.44,1.48)$ & \\
\hline & 9 and more years & & & $1.07(0.66,1.72)$ & \\
\hline \multirow{3}{*}{$\begin{array}{l}\text { Age of the } \\
\text { women }\end{array}$} & $15-24(\mathrm{RF})$ & - & - & - & \\
\hline & $25-34$ & $1.38^{*}(1.05,1.81)$ & $0.53^{* *}(0.37,0.78)$ & $0.94(0.6,1.46)$ & $0.66^{* *}(0.49,0.9)$ \\
\hline & $35-49$ & $1.48^{* *}(1.08,2.03)$ & $0.24^{\star \star}(0.15,0.4)$ & $0.34^{\star \star}(0.16,0.72)$ & $0.28^{\star \star}(0.19,0.43)$ \\
\hline \multirow{5}{*}{ Wealth quintile } & Poorest (RF) & - & & & \\
\hline & Poor & $1.17(0.85,1.62)$ & & & \\
\hline & Medium & $1.3(0.94,1.79)$ & & & \\
\hline & Rich & $1.18(0.85,1.64)$ & - & & \\
\hline & Richest & $1.52^{\star \star}(1.1,2.1)$ & & & \\
\hline \multirow{2}{*}{$\begin{array}{l}\text { Occupation of } \\
\text { the husband }\end{array}$} & Non-working (RF) & - & - & - & \\
\hline & Working & $1.95^{*}(1.13,3.36)$ & $0.38^{* *}(0.2,0.74)$ & $2.09(0.61,7.15)$ & \\
\hline \multirow{2}{*}{$\begin{array}{l}\text { Occupation of } \\
\text { the women }\end{array}$} & Non-working (RF) & - & & - & - \\
\hline & Working & $1.55^{\star *}(1.17,2.05)$ & & $0.25^{\star}(0.08,0.82)$ & $0.61^{\star}(0.4,0.92)$ \\
\hline
\end{tabular}

** Significant at 0.01 and $*$ Significant at 0.05 levels. 


\subsection{Religion}

Religion wise differential in using modern contraceptives was observed in our study. Fewer Muslim women used modern contraceptives as compared to their Hindu counterparts. A similar finding was observed by Chaurasia (2014) that across different religions, contraceptive prevalence has been found to be the lowest among Muslim women but the highest among Hindu women-resulting in highly skewed contraceptive method mix and Hindu-Muslim divide in the contraceptive use pattern in India. According to recent NFHS-4 report, the use of modern contraception or any type of contraceptive was high among the Hindus as compared to the Muslim women, while, use of traditional method of contraception was higher among Muslim women than their Hindu counterparts in India.

\subsection{Women as Heads of Households}

Interestingly, our study results revealed that use of modern contraception was low among the women who were the head of the households. Similarly, unmet need of family planning was low among the women who were not the head of the households. A comparable finding was observed in a study on Ethiopian women where results revealed that the odds of using long and permanent contraceptive methods was lower among the women living in female headed households as compared to the women living in male headed households (Fekadu et al., 2019). Contrary to this finding, results derived from three rounds of Demographic and Health Survey in Nigeria $(2003,2008,2013)$ found that women who were multiparous and from male-headed households were significantly more likely to report nonuse of modern contraception (Wang \& Cao, 2019).

\subsection{Number of Children}

Our study findings reflect that women having three children reported the highest use of modern contraceptive methods and the lowest was found among the women having no child. Similarly, women with parity of 3 reported highest use of modern contraception (66\%) whereas women with a parity of one had highest unmet need. Another study also confirmed that the maximum use of contraceptive was observed among employed women and who had more than 2 children was higher. Number of living children was likely to play a significant role in contraceptive use, since women who had $1-2$ children and who had more than two children were more likely to use contraceptives compared to women who had no children (Islam et al., 2016). Lwelamira et al. (2012) also found that likelihood of using modern contraceptives by woman increased significantly by when they were having higher number of living children. Mohammad et al. (2014) also found that women who had more than 5 children were almost three times less likely to use modern contraceptives compared with women who had no children. 


\subsection{Education of the Women}

It has been established in the extant literature that more educated women delay marriage and childbearing, and are more prone to use modern (i.e., effective) contraceptives, and ultimately have lower fertility than do women with less education (Larsson \& Stanfors, 2014). Analysis of data from 14 sub-Saharan African (SSA) countries also revealed that a woman's education is a stronger predictor of contraceptive use than her husband's education (Gubhaju, 2009; Uchudi, 2001). Hogan et al. (1999) also found that women's literacy and autonomy are, by far, the most significant forces in the movement toward lower fertility in the southern Ethiopia. Similarly, Lwelamira et al. (2012) found that chances of being current user of modern contraceptives by a woman increased significantly by having secondary education and higher and having higher number of living children. Among the women in Uganda, the likelihood of using contraception is associated with women's educational attainment (Asiimwe et al., 2014). But our study findings did not find that education of the women having much influence on contraceptive use and unmet need or demand satisfied. Hossain (2018) also found that although the prevalence of contraception use in Bangladesh did not vary by women's education, their occupation played a vital role.

\subsection{Husband's Education}

On the other hand, results also indicated that with increasing education of the husbands, the use of modern contraception also increased. Evidence from Nepal suggests that the husband's education had a greater influence than the wife's education on contraceptive use, especially in relation to male-controlled methods such as male sterilization and condom use (Gubhaju, 2009). On the other hand, a study using data from Bangladesh DHS showed that both partners' education levels are significant determinants of reported use of contraception (Islam et al., 2010). However, Kagwaa et al. (2008) found that although partner's education increased the likelihood of contraceptive use, a woman's education level was not associated with adoption of a method in Mali.

\subsection{Husband's Occupation}

In a similar way as husband's education, occupation of the husband also played a pivotal role in determining the use of modern contraceptives among the women in the study areas. The use of modern contraceptives increased when the husbands were employed as compared to the women whose husbands were not employed or were not working. This can be linked to the increased financial ability of the working couple/husbands to avail modern contraceptives. Hossain (2018) also found that in Bangladesh, women whose husbands were employed had higher prevalence of contraception use than those with an unemployed husband. Women whose husband had higher education showed slightly higher contraceptive use compared to those with an uneducated husband probably since males are the central decision maker of a family in Bangladesh. Zafar (1996) also found 
that family income, husband's occupation, child mortality, and age at marriage did not help to explain reproductive behaviour.

\subsection{Age of the Women}

Our study findings also indicated strong association between the age of women and modern contraceptive methods utilization. The use of modern contraceptive was increasing with increasing age of the women and on the other hand, unmet need was decreasing. Debebe et al. (2017) also found that as women's age increases from 15 to 34 ages old, the possibility of using contraceptive methods was increasing. Oyedokun (2007) found that among the women in Osun state of Nigeria, age was the main factor responsible for the general level of awareness of birth control methods and the use of contraception was positively related to the level of awareness of birth control methods. The practice of using contraception was more common among respondents in the 25 - 35 years age group, compared with the other younger or elder age groups (Islam \& Thorvaldsen, 2012).

The possible reason can be that when age increases, there is a chance that the women attain their desirable number of children or want to space the birth of the children. This can be also linked to increased awareness from peers/neighbors or relatives about modern methods of contraceptive use. On the contrary, Bogale et al. (2011) found that among women of child bearing age from urban and rural parts of southern Ethiopia, modern family planning use decision making did not have significant statistical difference with age groups, occupation and educational status in both settings.

\section{Conclusion}

The findings of the present study indicate a remarkably low prevalence of modern contraceptive use indicating considerable high unmet need. Women having three children reported the highest use of modern contraceptive methods and the lowest was found among the women having no child. Use of modern contraception was low among the women who were the head of the households. Working women, women belonging to richest wealth quintile, women whose husbands reported to be working and women from male headed households were less likely to have unmet need for family planning. This can be a concern and special emphasis of the policy makers should be on this since it is well researched that modern contraceptive use and addressing unmet need are of overriding importance in reducing pregnancy related morbidity, preventing unintended pregnancies that lead to abortion and will gradually improve reproductive well-being among women. Findings provide important insights for policy makers and researchers and thus invite more in-depth surveys for future. A longitudinal study that follows behavioral changes among the women can be more fruitful to ascertain the increased use of modern contraceptives and decreased use of unmet need among the urban poor. Results of the study which is specific to urban poor present a critical opportunity to reconsider the importance of 
family planning especially among the poorer section of the society and this calls for updating and revisiting program strategies addressing the urban poor and considering this as a public health priority.

The study has few strength and limitations too. One of the strength of this study is that the results are based on primary data collected among currently married women aged 15 - 49 of age from selected urban areas of Rajasthan and Uttar Pradesh. To provide a comparative understanding of the scenario, the findings were reported in light of the existing evidence. To contemplate the limitations, it should be noted that causal interferences were precluded as this present study shares the drawbacks of cross-sectional nature. This study used self-reported indicators of variables which increase the chances of reporting bias and social desirability. In addition, although contraceptive choice and use was examined, it is important to recognize that some couples have very limited choice in the methods they adopt and depends on the methods that are available and accessible to specific segments of the population. Also, sometimes lack of privacy at stores/shops limit the willingness of women to access contraceptive services and supply. Additionally, we also did not cover the side effects of contraception which may be one of the important reason women show inhibition in using certain kind of contraception. Further, findings of this study are based on urban poor population and may not be generalized.

\section{Acknowledgements}

Authors would like to acknowledge The United States Agency for International Development (USAID) for providing financial assistance to implement PAHAL Project. Authors also thank Ms. Eman Rahman for her constructive comments on the first draft of the paper.

\section{Conflicts of Interest}

The authors declare no conflicts of interest regarding the publication of this paper.

\section{References}

Achyut, P., Benson, A., Calhoun, L. M., Corroon, M., Guilkey, D. K., Kebede, E., Lance, P.M., Mishra, A., Nanda, P., O’Hara, R., Sengupta, R., Speizer, I, S., Stewart, J.F., \& Winston, J. (2016). Impact Evaluation of the Urban Health Initiative in Urban Uttar Pradesh, India. Contraception, 93, 519-525. https://doi.org/10.1016/j.contraception.2016.02.031

Adedini, S. A., Odimegwu, C., Imasiku, E. N., \& Ononokpono, D. N. (2015). Unmet Need for Family Planning: Implication for Under-Five Mortality in Nigeria. Journal of Health, Population, and Nutrition, 33, 187.

Asiimwe, J. B., Ndugga, P., Mushomi, J., \& Ntozi, J. P. M. (2014). Factors Associated with Modern Contraceptive Use among Young and Older Women in Uganda: A Comparative Analysis. BMC Public Health, 14, 926. https://doi.org/10.1186/1471-2458-14-926

Beson, P., Appiah, R., \& Adomah-Afari, A. (2018). Modern Contraceptive Use among Reproductive-Aged Women in Ghana: Prevalence, Predictors, and Policy Implications. 
BMC Women'S Health, 18, 157. https://doi.org/10.1186/s12905-018-0649-2

Bhattacharya, S. K., Ram, R., Goswami, D. N., Gupta, U. D., Bhattacharya, K., \& Ray, S. (2006). Study of Unmet Need for Family Planning among Women of Reproductive Age Group Attending Immunization Clinic in a Medical College of Kolkata. Indian Journal of Community Medicine, 31, 73-75.

Bogale, B., Wondafrash, M., Tilahun, T., \& Girma, E. (2011). Married Women's Decision Making Power on Modern Contraceptive Use in Urban and Rural Southern Ethiopia. BMC Public Health, 11, 342. https://doi.org/10.1186/s12905-018-0649-2

Bongaarts, J., \& Bruce, J. (1995). The Causes of Unmet Need for Contraception and the Social Content of Services. Studies in Family Planning, 26, 57-75. https://doi.org/10.2307/2137932

Brown, W., Druce, N., Bunting, J., Radloff, S., Koroma, D., Gupta, S., Siems. B., Kerrigan, M., Kress, D., \& Darmstadt, G. L. (2014). Developing the " 120 by 20 " Goal for the Global FP2020 Initiative. Studies in Family Planning, 45, 73-84. https://doi.org/10.1111/j.1728-4465.2014.00377.x

Casterline, J. B., \& Sinding, S. W. (2000). Unmet Need for Family Planning in Developing Countries and Implications for Population Policy. Population and Development Review, 26, 691-723. https://doi.org/10.1111/j.1728-4457.2000.00691.x

Chaurasia, A. R. (2014). Contraceptive Use in India: A Data Mining Approach. International Journal of Population Research, 2014, Article ID: 821436. https://doi.org/10.1155/2014/821436

Casterline, J. B., \& Sinding, S. W. (2000). Unmet Need for Family Planning in Developing Countries and Implications for Population Policy. Population and Development Review, 26, 691-723. https://doi.org/10.1111/j.1728-4457.2000.00691.x

Darroch, J. E., \& Singh, S. (2013). Trends in Contraceptive Need and Use in Developing Countries in 2003, 2008, and 2012: An Analysis of National Surveys. The Lancet, 381, 1756-1762. https://doi.org/10.1016/S0140-6736(13)60597-8

Darroch, J. E., Singh, S., \& Weissman, E. (2016). Adding It up: The Costs and Benefits of Investing in Sexual and Reproductive Health 2014-Estimation Methodology. Appendix B: Estimating Sexual and Reproductive Health Program and Systems Costs. New York: Guttmacher Institute.

Debebe, S., Limenih, M. A., \& Biadgo, B. (2017). Modern Contraceptive Methods Utilization and Associated Factors among Reproductive Aged Women in Rural Dembia District, Northwest Ethiopia: Community Based Cross-Sectional Study. International Journal of Reproductive BioMedicine, 15, 367. https://doi.org/10.29252/ijrm.15.6.367

Fekadu, G. A., Omigbodun, A. O., Roberts, O. A., \& Yalew, A. W. (2019). Factors Associated with Long Acting and Permanent Contraceptive Methods Use in Ethiopia. Contraception and Reproductive Medicine, 4, 9. https://doi.org/10.1186/s40834-019-0091-3

Freedman, R. (1987). The Contribution of Social Science Research to Population Policy and Family Planning Programme Effectiveness. Studies in Family Planning, 18, 57-82. https://doi.org/10.2307/1966698

Gubhaju, B. (2009). The Influence of Wives' and Husbands' Education Levels on Contraceptive Method Choice in Nepal, 1996-2006. International Perspectives on Sexual and Reproductive Health, 35, 176-185. https://doi.org/10.1363/3517609

Hogan, D. P., Berhanu, B., \& Hailemariam, A. (1999). Household Organization, Women's Autonomy, and Contraceptive Behavior in Southern Ethiopia. Studies in Family Planning, 30, 302-314. https://doi.org/10.1111/j.1728-4465.1999.t01-2-.X

Hossain, M. B., Khan, M. H. R., Ababneh, F., \& Shaw, J. E. H. (2018). Identifying Factors 
Influencing Contraceptive Use in Bangladesh: Evidence from BDHS 2014 Data. BMC Public Health, 18, 192. https://doi.org/10.1186/s12889-018-5098-1

International Institute for Population Sciences (IIPS) and ICF (2017). National Family Health Survey (NFHS-4), 2015-2016: India.

Islam, M. A., Padmadas, S. S., \& Smith, P. W. (2010). Consistency in Reporting Condom Use between Husbands and Wives in Bangladesh. Journal of Biosocial Science, 42, 563-572. https://doi.org/10.1186/s12889-018-5098-1

Islam, M. R., \& Thorvaldsen, G. (2012). Family Planning Knowledge and Current Use of Contraception among the Mru Indigenous Women in Bangladesh: A Multivariate Analysis. Open Access Journal of Contraception, 3, 9-16. https://doi.org/10.2147/OAJC.S25185

Islam, A. Z., Mondal, M. N. I., Khatun, M. L., Rahman, M. M., Islam, M. R., Mostofa, M. G., \& Hoque, M. N. (2016). Prevalence and Determinants of Contraceptive Use among Employed and Unemployed Women in Bangladesh. International Journal of $\mathrm{MCH}$ and AIDS, 5, 92. https://doi.org/10.21106/ijma.83

Kaggwa, E. B., Diop, N., \& Storey, J. D. (2008). The Role of Individual and Community Normative Factors: A Multilevel Analysis of Contraceptive Use among Women in Union in Mali. International Family Planning Perspectives, 34, 79-88.

https://doi.org/10.1363/3407908

Larsson, C., \& Stanfors, M. (2014). Women's Education, Empowerment, and Contraceptive Use in Sub-Saharan Africa: Findings from Recent Demographic and Health Surveys. African Population Studies, 28, 1022-1034. https://doi.org/10.11564/28-0-554

Lata, K., Barman, S. K., Ram, R., Mukherjee, S., \& Ram, A. K. (2012). Prevalence and Determinants of Unmet Need for Family Planning in Kishanganj District, Bihar, India. Global Journal of Medicine and Public Health, 1, 29-33.

Lwelamira, J., Mnyamagola, G., \& Msaki, M. M. (2012). Knowledge, Attitude and Practice (KAP) towards Modern Contraceptives among Married Women of Reproductive Age in Mpwapwa District, Central Tanzania. Current Research Journal of Social Sciences, 4, 235-245.

Machiyama, K., Casterline, J. B., Mumah, J. N., Huda, F. A., Obare, F., Odwe, G., Kabiru, C, Yeasmin, S., \& Cleland, J. (2017). Reasons for Unmet Need for Family Planning, with Attention to the Measurement of Fertility Preferences: Protocol for a Multi-Site Cohort Study. Reproductive Health, 14, 23. https://doi.org/10.1186/s12978-016-0268-Z

Matthews, Z., Channon, A., Neal, S., Osrin, D., Madise, N., \& Stones, W. (2010). Examining the "Urban Advantage" in Maternal Health Care in Developing Countries. PLoS Medicine, 7, e1000327. https://doi.org/10.1371/journal.pmed.1000327

Measure Evaluation (n.d.). Family Planning and Reproductive Health Indicators Database.

https://www.measureevaluation.org/prh/rh_indicators/family-planning/fp/unmet-need -for-family-planning

Mohammed, A., Woldeyohannes, D., Feleke, A., \& Megabiaw, B. (2014). Determinants of Modern Contraceptive Utilization among Married Women of Reproductive Age Group in North Shoa Zone, Amhara Region, Ethiopia. Reproductive Health, 11, 13. https://doi.org/10.1186/1742-4755-11-13

Montgomery, M. (2009). Urban Poverty and Health in Developing Countries. https://www.researchgate.net/profile/Mark_Montgomery3/publication/289498339_Popul ation_bulletin_Urban_poverty_and_health_in_developing_countries/links/5a9b061f0f7e 9be37966238b/Population-bulletin-Urban-poverty-and-health-in-developing-countries.p df 
Oyedokun, A. O. (2007). Determinants of Contraceptive Usage: Lessons from Women in Osun State, Nigeria. Journal of Humanities and Social Science, 1, 1-14.

Pachauri, S., \& Santhya, K. G. (2002). Reproductive Choices for Asian Adolescents: A Focus on Contraceptive Behavior. International Family Planning Perspectives, 28, 186-195. https://doi.org/10.2307/3088221

Rossi-Espagnet, A. (UNICEF) (1984). Primary Health Care in Urban Areas: Reaching the Urban Poor in Developing Countries. A State-Of-The-Art Report.

Sedgh, G., \& Hussain, R. (2014). Reasons for Contraceptive Non Use among Women Having Unmet Need for Contraception in Developing Countries. Studies in Family Planning, 45, 151-169. https://doi.org/10.1111/j.1728-4465.2014.00382.x

Sedgh, G., Ashford, L. S., \& Hussain, R. (2016). Unmet Need for Contraception in Developing Countries: Examining Women's Reasons for Not Using a Method. New York: Guttmacher Institute, 2015-2016.

Shifa, G. T., \& Kondale, M. (2014). High Unmet Need for Family Planning and Factors Contributing to It in Southern Ethiopia: A Community Based Cross-Sectional Study. Global Journal of Medical Research, 14, 20-32.

Uchudi, J. M. (2001). Spouses' Socioeconomic Characteristics and Fertility Differences in Sub-Saharan Africa: Does Spouse's Education Matter? Journal of Biosocial Science, 33, 481-502. https://doi.org/10.1017/S0021932001004813

Wang, C., \& Cao, H. (2019). Persisting Regional Disparities in Modern Contraceptive Use and Unmet Need for Contraception among Nigerian Women. BioMed Research International, 2019, Article ID: 9103928. https://doi.org/10.1155/2019/9103928

Westoff, C. F., \& Bankole, A. (1995). Unmet Need 1990-1994, DHS Comparative Studies, No. 16. Calverton, Maryland: Macro International Inc. https://doi.org/10.2307/2950797

Zafar, M. I. (1996). Husband-Wife Roles as a Correlate of Contraceptive and Fertility Behaviour. The Pakistan Development Review, 58, 145-170. https://doi.org/10.30541/v35i2pp.145-170

World Health Organisation (2015). Demand for Family Planning Satisfied with Modern Methods.

https://www.who.int/healthinfo/indicators/2015/chi_2015_74_family_planning.pdf 